\title{
Tundra Swans on the Upper Mississippi River
}

As fall foliage peaks in color on the bluffs along the Upper Mississippi River (UMR), the high-pitched bugling calls of thousands of tundra swans resonate from the once-quiet backwaters of the river. An abundant food supply and relatively undisturbed resting sites make the UMR an important staging area for tundra swans (Cygnus columbianus columbianus) during fall migration. Prior to the 1970s, only "small numbers" of tundra swans consistently stopped along the Mississippi River on their way to wintering grounds in the Chesapeake Bay. In recent years, fall swan numbers on the UMR have swelled to more than 30,000 during late November.

\section{Tundra swan viewing has become an increasingly popular fall recreational activity on the Upper Mississippi River.}

Tundra swans are the most common and widespread species of swans in North

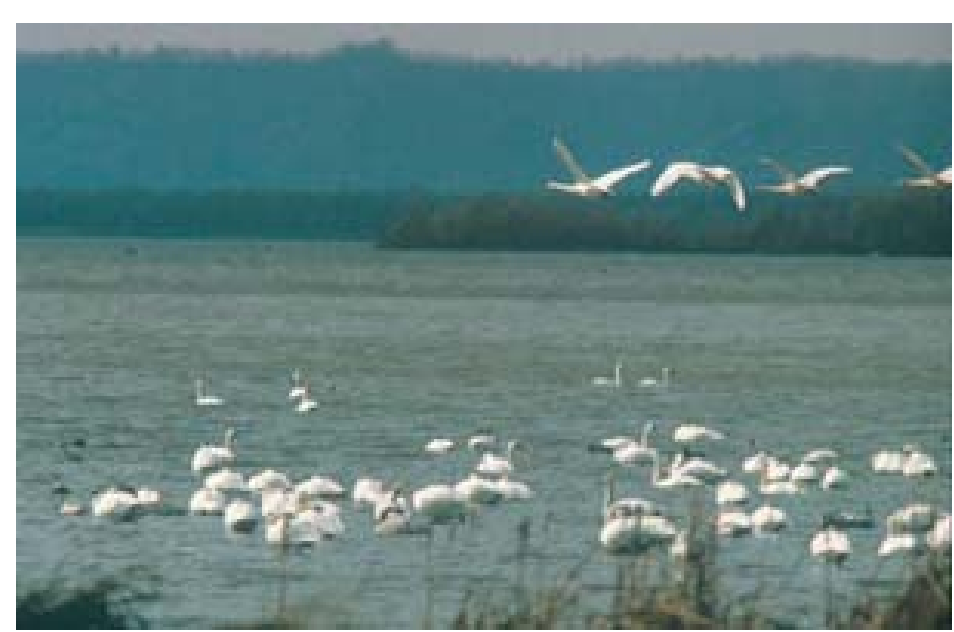

Tundra swans in Upper Mississippi River backwaters

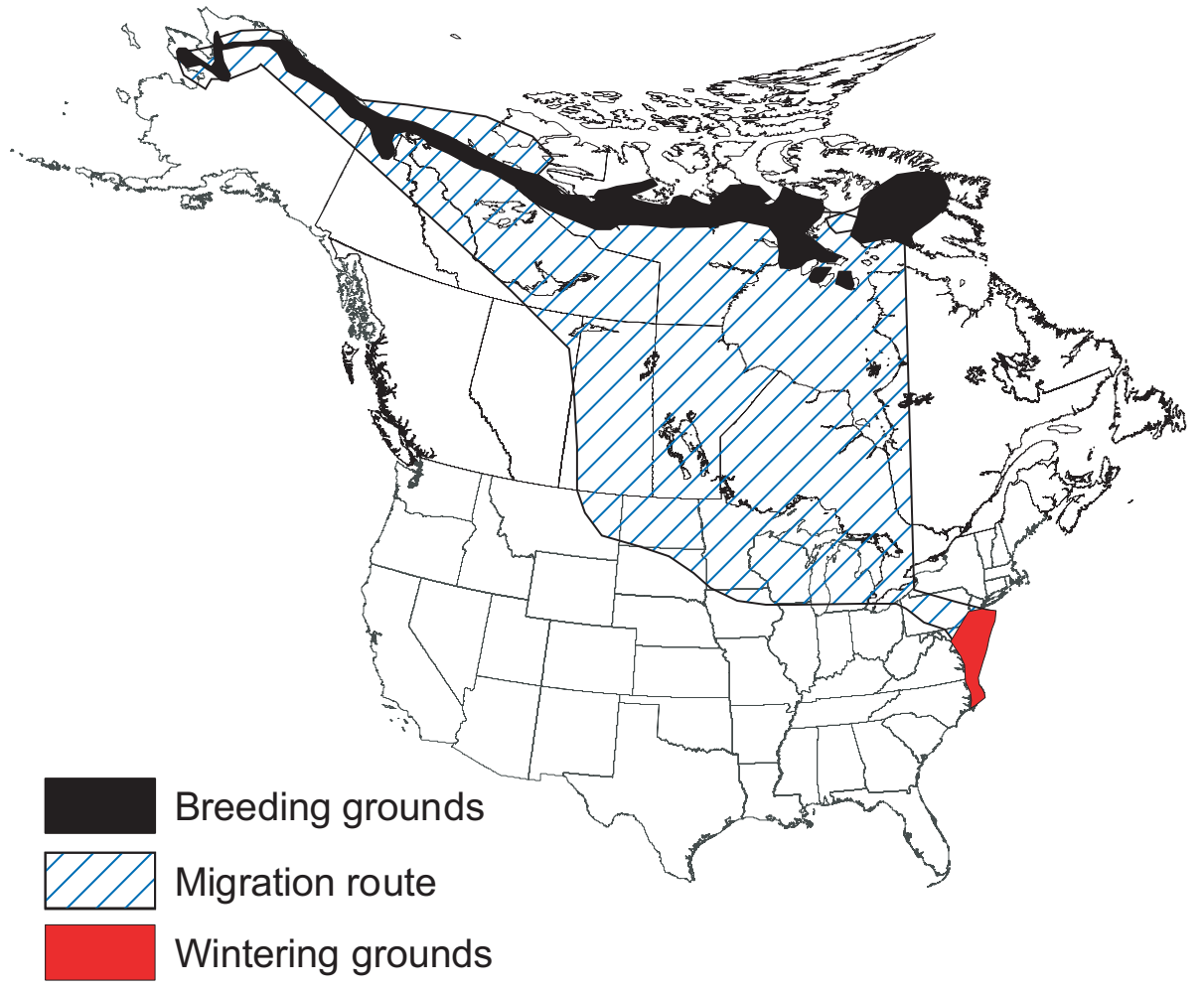

Range of the Eastern Population of tundra swans. This map is an interpretation of an electronic version derived from various sources.

America and are divided into two distinct populations: the Eastern and the Western Population. Birds migrating through the UMR are the Eastern Population of tundra swans. These birds breed along the arctic coast of Canada from Hudson Bay west to northwestern Alaska. Today the Eastern Population of tundra swans numbers around 100,000. The Eastern Population of tundra swans migrate south through the prairie provinces of Canada, the Dakotas, and
Minnesota to reach the UMR by mid to late October. The last swans depart the UMR with freeze-up, usually in mid to late December. Scientists estimate that about $25 \%$ of the Eastern Population of tundra swans, including about half of all young produced, use the UMR during fall migration.

On the arctic breeding grounds, swans begin nesting as early as spring thaws permit because their young need about 60 to 70 days to develop after hatching. Tundra swans first breed when they are 2 to 3 years old and breeding pairs mate for life. Female tundra swans prefer to nest on shores, points, islands, or vegetated hummocks of lakes, ponds, or marshes. The females lay an average of six eggs over 6 to 10 days. The young, called cygnets, hatch after 31 to 32 days of incubation. Cygnets are brownish-






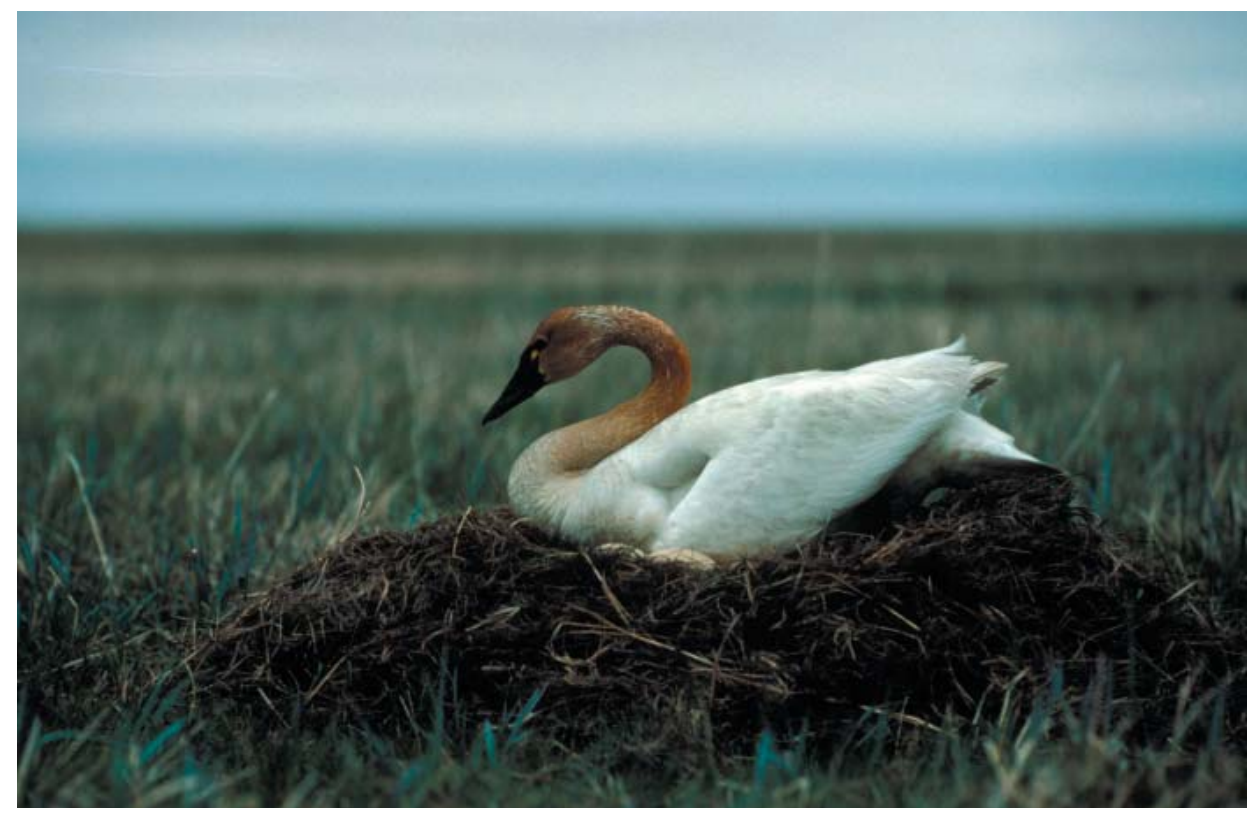

foods for tundra swans on the UMR. An adult swan consumes an estimated 6.2 pounds of tubers per day on the UMR.

Tundra swan viewing has become an increasingly popular fall recreational activity on the UMR. The best time to view tundra swans is from mid-October through mid-November. Popular viewing areas include the Watchable Wildlife Observation Platform at Rieck's Lake Park near Alma, Wisconsin, and along Highway 26 south of Brownsville, Minnesota.

Scientists from the Upper Midwest Environmental Sciences Center, in collaboration with the U. S. Fish and Wildlife Service, are studying the ecology

Female tundra swan on nest in Arctic breeding grounds

gray for their first 6 to 8 months, whereas the plumage of adult tundra swans is completely white. A small yellow spot is often visible at the base of the adult's black bill. Tundra swans weigh between 13 to 20 pounds, average about 3 feet in height and have a wingspan of 6 to 7 feet. Family groups, consisting of white adults and gray cygnets, can easily be identified on the UMR. By the time the birds reach the UMR, the average number of young per family is about two.

Along the UMR, tundra swans feed primarily on the leaves, stems, and tubers of aquatic plants. Arrowhead, sago pondweed, and wildcelery grow in abundance in shallow marshes and impounded areas and are important

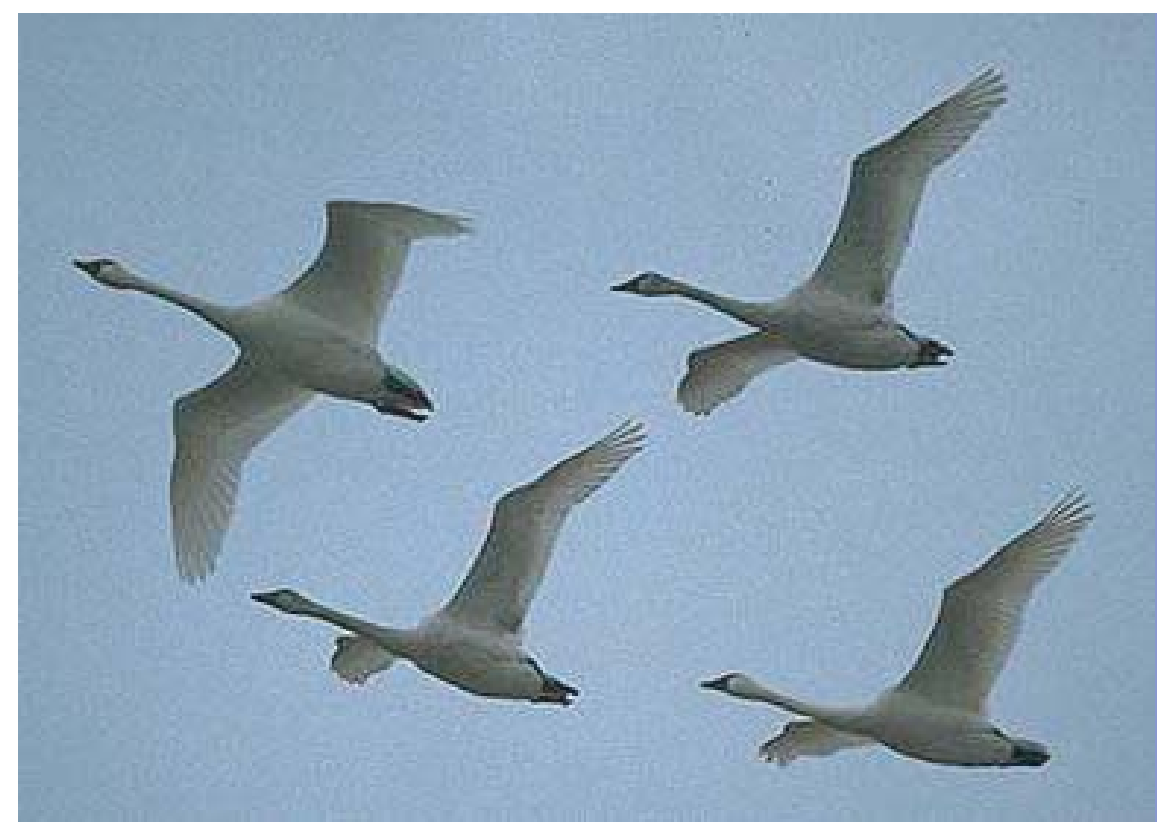

Photo by Victor Fazio III and used with permission

\section{For more information, contact}

Kevin Kenow

USGS Upper Midwest Environmental Sciences Center 2630 Fanta Reed Road

La Crosse, WI 54603

Phone: 608.781.6278

Fax: 608.783.6066

kkenow@usgs.gov

\section{http://www.umesc.usgs.gov/}

of tundra swans during fall migration. We are using digital aerial photography to determine the daytime distribution and abundance of swans on the UMR and thermal infrared imaging to document their nighttime location. We will relate swan locations to the availability and distribution of food resources within selected areas of the UMR. We are also interested in how swans might affect the availability of arrowhead, wildcelery, and sago pondweed for other birds. River managers and biologists will use this information to develop management strategies that enhance the UMR as an important stopover area for swans. 